\title{
O DIÁLOGO DE SABERES SOCIOAMBIENTAIS COMO ALTERNATIVA PARA A CRIAÇÃO DE UM MUNDO POSSÍVEL EM TEMPOS DE CRISE CIVILIZATÓRIA
}

\author{
THE DIALOGUE OF SOCIO-ENVIRONMENTAL KNOWLWDGE AS AN \\ ALTERNATIVE FOR THE CREATION OF A POSSIBLE WORLD IN TIMES OF A \\ CIVILIZATION IN CRISIS
}

\section{EL DIÁLOGO DE SABERES SOCIO AMBIENTALES COMO ALTERNATIVA PARA LA CREACIÓN DE UN MUNDO POSIBLE EN TIEMPOS DE CRISIS CIVILIZATORIA}

\author{
Antonio Marcio Haliski ${ }^{1}$ \\ https://orcid.org/0000-0001-8373-8796 \\ Rogerio Baptistella ${ }^{2}$ \\ https://orcid.org/0000-0002-2838-1074
}

Submissão: 07/04/2021 / Aceito: 12/07/2021 / Aceito: 04/02/2022.

\begin{abstract}
Resumo
O tempo de crise civilizatória que vivemos requer um grande esforço para que possamos superá-lo. As alternativas são várias e apontam para necessárias rupturas em nossos modos de agir e pensar sobre a vida na Terra. Neste texto, destacaremos os avanços e possíveis formas de diálogo de saberes socioambientais e que nos induzem ao (re)conhecimento de múltiplos saberes, que não apenas aqueles do universo acadêmico; por isso, a necessidade de um diálogo que passa pela compreensão de outro mundos possíveis, ou seja, das realidades vividas por povos originários, populações tradicionais, camponeses, até os saberes eclesiásticos ou de suas lideranças que apontam para o buen vivir. Para tanto, traremos uma discussão atualizada sobre o que se entende por diálogo de saberes socioambientais e a sua intrínseca ligação com a educação ambiental - não aquela que meramente está presente em componentes curriculares, mas como modo de se viver no mundo - e também o tema do diálogo a partir da Encíclica Laudato Si', tendo em vista as importantes manifestações do Papa Francisco no cenário atual. Encerramos com a afirmação de que as respostas para os problemas atuais estão nos modos de vidas que acenam para um sistema socioeconômico não capitalista.
\end{abstract}

Palavras-chave: Diálogo de saberes; Modos de vida; educação ambiental; Saberes tradicionais.

\begin{abstract}
The crisis we are experiencing in our civilization requires a great deal of effort to overcome it. There are many alternatives which indicate necessary paradigm shifts in our ways of acting and thinking about life on Earth. In this text we will highlight the advances and possible forms of dialogue of socio-environmental knowledge that lead us to know and recognize multiple forms of knowledge and not only those that belong to the academic world. Therefore, it is necessary a dialogue that involves understanding other possible worlds, in other words, perceive the realities

\footnotetext{
${ }^{1}$ Doutor em Sociologia pela Universidade Federal do Paraná (UFPR). Docente do Programa de Pós-graduação em Ciência Tecnologia e Sociedade do Instituto Federal do Paraná - Paranaguá/PR (PPGCTS). antonio.haliski@ifpr.edu.br

${ }^{2}$ Doutor em Filosofia pela Universidade do Vale do Rio dos Sinos (UNISINOS). Docente do Programa de Pósgraduação em Ciência Tecnologia e Sociedade do Instituto Federal do Paraná - Paranaguá/PR (PPGCTS). rogerio.baptistella@ifpr.edu.br
} 
faced by native peoples, traditional populations, peasants, even the ecclesiastical knowledge or of their leaders that point out to the concept of "buen vivir" (good living). For this reason, we are going to present the most recent discussions about the dialogue of socio-environmental knowledge and its intrinsic relationship with environmental education - not that one merely present in curricular components or subjects, but as a way of living in the world - and also the theme of dialogue contained in the Encyclical Laudato $\mathrm{Si}^{\prime}$, taking into account the important assertions of Pope Francis about the current scenario. We conclude by stating that the responses to the current problems lie in the ways of life that point to a non capitalist socio-economic system.

Keyword: Dialogue of knowledge; Ways of life; Environmental education; Traditional knowledge.

\section{Resumen}

La época de crisis de civilización que vivimos requiere de un gran esfuerzo para poder superarla. Las alternativas son muchas y apuntan a las disrupciones necesarias en nuestra forma de actuar y pensar la vida en la Tierra. En este texto destacaremos los avances y posibles formas de diálogo del conocimiento socioambiental y que nos inducen al (re)conocimiento de de múltiples saberes, que no son solo los del universo académico; de ahí la necesidad de un diálogo que implique comprender otros mundos posibles, es decir, las realidades vividas por los pueblos originarios, las poblaciones tradicionales, los campesinos, incluso el saber eclesiástico o sus líderes que apuntan al buen vivir. Para ello, traeremos una discusión actualizada sobre qué se entiende por diálogo de saberes socioambientales y su conexión intrínseca con la educación ambiental, no una mera presencia en los componentes curriculares, sino como una forma de vivir en el mundo, y también el diálogo temático basado en la Encíclica Laudato Si en vista de las importantes manifestaciones del Papa Francisco en el escenario actual. Terminamos con la afirmación de que las respuestas a los problemas actuales se encuentran en las formas de vida que atraen a un sistema socioeconómico no capitalista.

Palabras Clave: diálogo de saberes; formas de vida; educación ambiental; conocimiento tradicional.

\section{INTRODUÇÃO}

No contexto atual de avanço crescente do neoliberalismo, verificamos inúmeros pesquisadores e pesquisas que focam nos povos e populações tradicionais e seus modos de vida, como alternativa para este sistema político-econômico que é avassalador sobre os direitos coletivos e os usos dos recursos naturais. Trata-se de um esforço que não se restringe ao Brasil, mas a América Latina e nível mundial como um todo, pois a defesa da nossa "Casa Comum" ultrapassa qualquer fronteira geopolítica. Por isso, cientistas das mais variadas formações (geógrafos, filósofos, teólogos, biólogos, historiadores, sociólogos, agrônomos, antropólogos...) se unem em torno dos direitos coletivos e somam-se aos atores de povos e comunidades para construírem possibilidades de diálogos que resultem em ações e políticas que se materializem em associações, redes de pesquisas e extensão, escolas e universidades com currículos diferenciados. 
Desta forma, o objetivo deste artigo é discorrer sobre o que se entende por diálogo de saberes socioambientais e seu fundamento na educação ambiental para que se possa apontar uma alternativa na construção de pontes entre universidades-escolas e comunidades pois, em nossa análise, o principal motor do desenvolvimento de territórios e da construção de uma nação pautada em outros valores, são os constituídos e pautados no buen vivir. Uma discussão mais aprofundada pode ser encontrada em trabalhos como Salvador Schavelzon (2015) "Plurinacionalidad y vivir bien/buen vivir". Mas, em linhas gerais, trata-se de um movimento e também de práticas onde temos uma (re)valorização dos saberes de povos originários e populações tradicionais. Reconhecidamente os povos andinos são as principais referências, por se tratar de uma resistência e enfrentamento ao capitalismo a partir de modos de vida que se revelam em uma trama de relações complexa da(s) sociedade(s) com a natureza. E neste contexto, chamamos a atenção para a educação ambiental no sentido dos modos de vidas que buscam uma relação com a natureza pautada no respeito e no sentimento de pertença a mesma e não meramente como um componente curricular ou tema transversal a ser cumprido nos currículos escolares. Assim, falaremos a partir de nossa experiência de ensino, pesquisa e extensão desenvolvida junto aos povos e comunidades tradicionais (ações e constituição de redes), tendo como base um extenso e atualizado referencial teórico.

Dessa forma, iniciaremos uma discussão sobre o que entendemos por diálogo de saberes, passamos para o sentido de educação ambiental atrelado a ele e avançamos para situações atuais que envolvem desde as articulações entre redes de pesquisadores até chegarmos na encíclica papal Laudato Si que nos evidencia a busca por alternativas ao modelo socioeconômico vigente a partir de uma instituição religiosa com grande força na América Latina, especificamente no Brasil. A lógica é mostrarmos distintos movimentos dentro e fora do meio acadêmico que apontam para a (re)valorização de outros saberes. Nessa linha de pensamento Skewes (2017) defende que precisamos tornar o mundo mais indígena, por conta dos seus saberes e práticas, assim como Leff (2019) e Lacey (2019) mostram que é necessário e possível o diálogo entre distintas formas de concebermos a realidade, ou seja, entre saberes tão importantes quanto aqueles produzidos dentro de universidades. Finalizamos apontando que um outro mundo é possível e passa necessariamente pela capacidade das universidades em dialogarem com povos e comunidades tradicionais, a ponto de revalorizarem suas práticas que são, em si, uma forma de contrapor a capitalização de tudo. 


\title{
SOBRE O DIÁLOGO DE SABERES
}

\begin{abstract}
El diálogo de saberes no se conduce por la fórmula de racionalidad comunicativa basada en significados objetivos y en códigos de racionalidad preestablecidos por un saber de fondo común; el diálogo de saberes es el encuentro de interlocutores que rebasa toda concep-tualización, toda teoría y toda finalidad guiada por una racionalidad, que antepone la justificación de una racionalización a la razón y la justicia del Otro. (LEFF, 2003,p.24)
\end{abstract}

A primeira questão a evidenciarmos é que o diálogo de saberes se relaciona diretamente com a horizontalidade de relações entre os envolvidos (HALISKI et al, 2016); neste sentido, a grande maioria de escolas e universidades já se mostram como uma afronta a esta lógica, visto que as relações são verticais desde a relação professor-aluno até a formatação dos currículos. Isto se aplica a várias instituições brasileiras e se manifesta, por exemplo, no desenvolvimento de políticas públicas (Silva, 2006), ou seja, não é uma construção a partir da base, mas o inverso - são imposições. Por este motivo, a maioria dos enfrentamentos frente a ações de cima para baixo vem a partir de discussões sobre os recursos naturais. Isto porque modismos como a criação de parques ecológicos raramente vem acompanhados de discussões coletivas. Assim, não é raro encontrarmos afirmações como a de Floriani (2008) ao exigir uma nova racionalidade ambiental que dependerá do concurso ou do consórcio de distintas estratégias, para fragilizar a racionalidade instrumental dominante. Trata-se da valorização da ciência, mas também de outros saberes sociais com base na tradição (ex, quilombolas, faxinalenses, quebradeiras de coco entre outros).

Isso mostra a necessidade da utilização de estratégias para que se utilizem os recursos naturais dentro de uma nova racionalidade ambiental. É neste contexto que Leff (2001) fala em revalorização de um conjunto de saberes sem pretensão de cientificidade. Assim, entende-se que (re)valorizar os saberes "populares", "tradicionais", "sociais", seja qual for o nome dado a eles, não significa supervalorizá-lo ou diminuir a importância da ciência, isto sim, buscar alternativas para o diálogo necessário entre os conhecimentos citados.

Segundo Leff (2003), a racionalidade ambiental encontra sua morada no saber ambiental. E, este por sua vez, não pode confinar-se nos conhecimentos científicos constituídos. Portanto, o diálogo de saberes se inscreve numa política da diferença, a qual ultrapassa o pensamento ecologista e o sistema de saberes existentes, constituindo-se no encontro com a alteridade. A construção da racionalidade ambiental conduz à desconstrução das lógicas de conhecimento e de poder dominantes, abrindo as vias para outras significações da natureza desde a cultura. 
administración del ambiente. La racionalidad ambiental es una teoría que orienta una praxis a partir de la subversión de los principios que han ordenado y legitimado la racionalidad teórica e instrumental de la modernidad. Es una racionalidad -en sentido weberiano- que articula una racionalidad teórica e instrumental con una racionalidad sustantiva; es una racionalidad que integra el pensamiento, los valores y la acción; es una racionalidad abierta a la diferencia, a la diversidad y pluralidad de racionalidades que definen y dan su especificidad e identidad a la relación de lo material y lo simbólico, de la cultura y la naturaleza (LEFF, 2003,p.33).

Análises como a de Leff podem ser reforçadas à medida que surgem situações como aquela apontada por Viveiros de Castro (2002) ao se referir à Amazônia, pois boa parte dela seria o resultado de milênios de manipulação humana e, ao contrário do que comumente se imagina, afirma que as florestas antropogênicas apresentam maior biodiversidade que as florestas nãoperturbadas. Nesta mesma linha de raciocínio Porto-Gonçalves (2017) enfatiza que a Amazônia não pode ser vista somente como um bioma com destaque para sua fauna e flora, mas também pela diversidade de povos e culturas que representam mais de 180 línguas faladas neste espaço e que co-evoluiram com a floresta. Esse tipo de resultado, com base em saberes vernaculares, já foi evidenciado em estudos, como em Nicolas Floriani (2007), ao apontar que a racionalidade dos agricultores de Rio Branco do Sul - PR não está vinculada a práticas intensivas e degradantes do solo, por este motivo abandonaram a utilização de agrotóxicos e retornaram às suas práticas tradicionais.

Este saber-fazer (ACOSTA, 2012) está sendo constatado em várias pesquisas sobre populações tradicionais e saberes vernaculares como é o caso dos estudos de Strachulski (2014) sobre os saberes tradicionais de agricultores ou mesmo de Staniski (2016) sobre os saberes mateiros de populações tradicionais. Em ambos os casos, a valorização de conhecimentos tradicionais e científicos são acionados com o propósito do diálogo de saberes e uma necessária ressignificação da universidade na busca incessante por uma ciência que de fato seja pública (FLORIANI, 2015).

Assim:

El diálogo de saberes demanda palabras que los articulen en algo más que un postulado o una axiomática, de una racionalidad instaurada en una realidad, para dar coherencia y consistencia a aquello que hoy empieza a manifestarse en el encuentro y enlaziamiento de discursividades, de pensamientos, de hablas y de acciones que plantea la relación entre el ser y el saber. Se trata del campo de una política de la diferencia que pone en movimiento una relación del ser y lo real, con u Otro y con el Infinito. (LEFF, 2003,p.31)

É nesse contexto que Floriani (2008) afirma que o diálogo de saberes e a racionalidade ambiental seriam produções discursivas e práticas sociais que não teriam preocupações maiores com qualquer tipo de ruptura epistemológica ou qualquer tipo de pureza científica, pois se trata de 
inaugurar um campo de saber e de conhecimento com articulações intra (disciplinares) e extracientíficas.

\title{
SOBRE A EDUCAÇÃO AMBIENTAL
}

Leff (2009) nos evidencia uma crise ambiental que, por sua vez, também o é da razão, do pensamento e do conhecimento. É aí que ganha destaque a educação ambiental.

\begin{abstract}
A educação ambiental emerge e se funda em um novo saber que ultrapassa o conhecimento objetivo das ciências. A racionalidade da modernidade pretende por à prova a realidade, colocando-a fora do mundo que percebemos com os sentidos e de um saber gerado na forja do mundo da vida. O saber ambiental integra o conhecimento racional e o conhecimento sensível, os saberes e os sabores da vida. O saber ambiental prova a realidade com saberes sábios que são saboreados, no sentido da locução italiana asaggiare, que põe à prova a realidade degustando-a, pois se prova para saber o que se pensa, e, se a prova da vida comprova o que se pensa, aquele que prova se torna sábio. Dessa forma, restaura-se a relação entre a vida e o conhecimento. (LEFF, 2009,p.18)
\end{abstract}

Com relação ao diálogo de saberes, Leff (2009) afirma que ele se produz no encontro de identidades. É a entrada do ser constituído por intermédio de sua história até o inédito e o impensado, até uma utopia arraigada no ser e no real, construída a partir dos potenciais da natureza e dos sentidos da cultura. Assim, o ser, para além de sua condição existencial geral e genérica, penetra o sentido das identidades coletivas que constituem o crisol da diversidade cultural em uma política da diferença, mobilizando os atores sociais para a construção de estratégias alternativas de reapropriação da natureza em um campo conflitivo de poder, no qual se desdobram sentidos diferenciados e, muitas vezes, antagônicos, na construção de um futuro sustentável.

\begin{abstract}
A educação ambiental recupera assim o sentido originário da noção de educere, como deixar sair a luz; não como um novo iluminismo da coisa, nem como o despregar-se do objeto ou a transmissão mimética de saberes e conhecimentos, mas sim como a relação pedagógica que deixa ser ao ser, que favorece a que as potências do ser, da organização ecológica, das formas de significação da natureza e dos sentidos da existência se expressem e manifestem. A educação ambiental é o processo dialógico que fertiliza o real e abre as possibilidades para que se chegue a ser o que ainda não se é. (LEFF, 2009,p.23)
\end{abstract}

Quando se afirma a necessidade do diálogo de saberes e que resultará numa educação ambiental fruto de uma construção coletiva, emerge a questão: como fazer isso? Em grande medida Luna e Moya (2008) apontam um caminho que passa pela escola. Trata-se do reconhecimento dos limites da formação pedagógica e a necessidade de superá-los através da criação de espaços de diálogos de saberes que propiciem uma relação da escola com a comunidade e que se manifeste em projetos de investigação. 
La formación del docente y de los estudiantes, debe tomar en cuenta a la enseñanza como proceso abierto al pensar creativo, al encuentro con la identidad en el reconocimiento de lo simbólico, vivido, soñado. Este es el camino para que el sujeto se pueda habitar, dándole a la formación un sentido de libertad para aprender e interpretar. Se trata de superar el concepto de educación y de escuela que ha estado vinculado a lo preestablecido y a la reproducción de estados culturales. (LUNA e MOYA, 2008,p.457)

Esta situação permite pensarmos na formação do professor tanto na universidade quanto na sua formação continuada. Os alunos e a comunidade farão parte deste processo.

\begin{abstract}
La formación del docente debe abrirse a formas de comprensión alejadas de la concepción de sujeto cosificado, de procesos de alienación que manipulan al sujeto, a la realidad y a las acciones del ser para transformar su entorno. Lo contradictorio y lo diverso nutre la posición centrada en el diálogo de saberes, éste se expresa como diálogo de la complejidad, por lo tanto, hace inclusiva la búsqueda del conocimiento más allá de lo aparente. Se debe considerar que lo que acontece es proceso constituyente, por esto la intersubjetividad es intercambio sobre este acontecer que se expresa como concientización. En este sentido, en el espacio escolar, es necesario seguir el acontecimiento en su desarrollo; así, podría surgir el compromiso ético que tendría mejores posibilidades en el enlace escuela-saber-comunidad. (LUNA e MOYA, 2008, p. 457)
\end{abstract}

Como resultado, espera-se que o diálogo de saberes resulte em problematizações da realidade e ao mesmo tempo em que sirva para obtenção de respostas aos questionamentos que foram postos.

En esta lógica, el diálogo intersubjetivo favorece la posibilidad de transversar propuestas, este proceso se corresponderá con el pensar individual de cada sujeto y el intercambio de las diversas posiciones. Así, se cruzan saberes que permiten la explicación o generación de otras dudas, este cruce de explicaciones o de interrogantes da cuenta de lo complejo de lo real. (LUNA e MOYA, 2008, p. 457)

Assim,

$\{\ldots\}$ el diálogo de saberes debe constituir-se en el cruce de cultura pública y cultura académica; en este sentido, se debe superar la creencia de que todo conocimiento escolar representa lo válido y lo que proviene de lo cotidiano debe ser rechazado. El diálogo de saberes representa la recuperación del enlace con la realidad, es actividad para que aflore la intersubjetividad como expresión de intercambio entre el tiempo cultural y la necesidad de resignificar el valor del formar-se desde una perspectiva de creatividad. (LUNA e MOYA, 2008, p. 460)

\title{
CRIANDO PONTES: O DIÁlogo DE SABERES COMO AÇÃo FRENTE Às DESIGUALDADES EXISTENTES
}

[...] hay que dar cuenta de la imposibilidad de recrear procesos sociales desde posiciones unilaterales. Hoy el encuentro, el diálogo, la negociación hacen parte de nuevos rituales que buscan llegar a consensos y a agendas de negociación política. Esto ha implicado que los sectores dominantes trabajen con especial énfasis las estructuras comunicacionales que 
les permiten redescubrir la dimensión social e histórica, la tradición cultural como reserva de esperanzas y de sentidos. La comprensión de la inviabilidad de propuestas autoritarias y el reconocimiento de esa tradición cultural fuente de sentidos de vida, lleva a pensar que los procesos de educación popular e investigación comunitaria lejos de cooptar, homogeneizar, asimilar la diferencia o la contradicción tendrían que operar desde y con procesos comunicativos que permitan esclarecer fines, mostrar la singularidad, la diversidad, la diferencia y la desigualdad; facilitando acontecimientos y proyectos orientados a recrear las formas de resignificar la participación y la solidaridad, en un sistema determinado por la ley del más fuerte en lo cultural, social, político y económico. (GUISO, 2000, p.11)

São várias as dimensões (políticas, econômicas, culturais) e escalas (local, territorial, regional, nacional) que o diálogo de saberes pode atingir. Podemos exemplificar a partir dos trabalhos da Rede Casla-Cepial[1] e sua(s) forma(s) de atuação. Iniciamos pela perspectiva de uma identidade latino-americana da Rede, pois ela prega a integração entre povos e culturas, de modo que tenhamos o Buen vivir. Isto significa movimentos, instituições e sujeitos, visto que também é formado por eles, atuando coletivamente em escalas micro e macro. No plano macro e também político, temos as relações e acordos firmados entre interessados em compor o grupo, ou seja, uma Rede que não tem centro e ao mesmo tempo constitui-se por ações, e estas têm o intuito de defender os interesses/direitos coletivos. No plano micro temos o trabalho desenvolvido por pesquisadores e movimentos sociais junto às comunidades, como é o caso dos trabalhos desenvolvidos com faxinalenses no centro sul do Paraná - via departamento de Geografia da Universidade Estadual de Ponta Grossa-UEPG[2]. É o trabalho in loco a partir de levantamento de demandas da(s) comunidade(s) como os conflitos por terra e território, direito de usos dos recursos naturais e mapeamentos. Outro passo é o encaminhamento das questões através da constituição de equipes para tal. Nesta etapa se insere o desenvolvimento de projetos como a cartografia social, criação de selos ambientais ou mesmo o encaminhamento jurídico das demandas. Em todo o processo alunos, comunidade, universidade e movimentos participam.

Do abordado até aqui, emergem ao menos três questões no plano acadêmico:

a) o sentido da tradução (SANTOS, 2004) nos estudos de povos e comunidades, ou seja, como e a partir de quê elementos/bases teóricas e conceituais os intelectuais traduzem o que estão pesquisando, pois isto se revela em pesquisa, textos, artigos, que podem ser, até mesmo, questionados por outros tradutores/intelectuais, mas acima de tudo é uma forma de valorizar a diversidade de conhecimentos existentes e não uma visão unilateral de ciência. Trata-se de uma celebração da diversidade (SANTOS, 2004). Talvez uma questão que pode ilustrar isso é questionamento em torno do(s) objeto(s) de análise: estamos vendo e (des)escrevendo o que realmente é? Por isso, dentre os elementos da sociologia de Boaventura o que temos é um 
questionamento sobre os limites da ciência moderna, mostrando que existem outras "razões" - não somente aquela do conhecimento acadêmico ocidental - e que o conhecimento é influenciado pela realidade (Santos, 2002). Assinale-se que ao analisar a realidade existe uma interferência direta nela, pois como assinala Boaventura, o trabalho de tradução cria situações para emancipações sociais concretas de grupos sociais concretos (SANTOS, 2004).

b) O plano prático-operacional, a articulação com os movimentos sociais, instituições e demais sujeitos, numa relação de horizontalidade - Esta situação segue a linha descrita acima por Boaventura e busca um rompimento com a imposição de ideias, políticas, ações, desde a universidade ou sujeitos (re)produtores de conhecimento.

\begin{abstract}
Evidentemente que nós estamos no extremo ocidente, até geograficamente. O extremo ocidente é uma categoria como a epistemologia do sul, que não corresponde apenas a uma definição geográfica de lugar. Mas esta epistemologia do sul, ou este extremo ocidente, é reveladora também de uma historicidade, de uma formação social diversa, por exemplo, da outra face da epistemologia do norte ou do núcleo duro do Ocidente. Todos os nossos autores, as nossas referências, a nossa formação, inclusive escolar, se remete a essa epistemologia do norte. (FLORIANI, 2016, p. 183)
\end{abstract}

Esta afirmação mostra a necessidade de reconhecimento de outras epistemologias que não aquela hegemônica e que domina, inclusive, os bancos escolares e que negam os saberes historicamente constituídos a partir do saber-fazer de povos e comunidades.

É por isso que nós vamos sempre acrescentando a essa ideia de uma epistemologia da diversidade uma epistemologia cultural, uma epistemologia híbrida, uma epistemologia política, a relação da ciência com os valores, a relação do conhecimento com a cultura. (FLORIANI, 2016, p. 183)

Destaque-se que neste processo o pesquisador interage com o objeto de análise (realidade) e sua prática revela muito do que vemos nas práticas extensionistas. Situações como estas estão sendo desenvolvidas em inúmeros projetos, como é o caso mostrado por Haliski et al (2016) no desenvolvimento do projeto Pibid-ilhas, pois a metodologia foi de contato com a comunidadeescola-universidade, nesta relação horizontal, ou seja, os alunos universitários (re)conheciam a ilha e por consequência a escola e a comunidade local para, a partir daí, elaborarem seus planos de aula pensando este contexto. Trata-se da universidade na escola-comunidade e vice-versa, mas não somente no sentido de estar ali, mas também na intervenção.

c) O plano ideológico a (re)produção de ideias com este viés "intervencionista" - como os três itens estão interligados, neste momento faremos uma reflexão que envolve a produção do conhecimento e como ele se manifesta na própria academia. 
Sin embargo, las modas intelectuales corresponden a eventos más o menos estables, de corta, mediana y larga duración pero que pueden cambiar radicalmente de acuerdo a la pérdida de interés o cuando son deslegitimados y desvalorizados por los efectos ideológicos producidos por la pérdida de interés o cuando los temas sufren un importante déficit mediático e incredulidad y depreciación; hay una especie de bolsa de valores simbólicos que mide lo que más está en boga de autores y temas que empiezan a ganar o perder fuerza según las circunstancias.(FLORIANI, 2015, p. 2)

Os modismos na pesquisa acadêmica são uma realidade, no entanto, como já assinalado em outro momento, temos um predomínio de obras de autores europeus e da América do Norte nos currículos universitários. Eles ditam o que e como fazer pesquisa/ensino. Essa cópia de modelos não se restringe a academia, mas também ao que se entende por desenvolvimento/políticas, como aquelas que pregam a perspectiva do desenvolvimento territorial e que, por assumirem esta condição de mera transposição de modelos, geralmente não funcionam em nosso país, como é o caso da implantação de arranjos produtivos locais - APLs (HALISKI, 2007). Por este motivo outra vertente vem se consolidado na América Latina e tem como propósito mostrar outras possibilidades.

Es bien verdad que la europeización de los marcos teóricos siempre estuvo presente en los centros de pensamiento latinoamericano, por razones coloniales y que autores autóctonos intentaban oponerse, aprovechando la ola de la contestación en contra de la colonialidad del saber y del poder (Quijano, Mignolo, etc.). Las raíces de esta contestación se ubican en el mismo período en que se gestaban las teorías de la dependencia o de la resistencia al colonialismo e imperialismo (Fanon, Amin, Casanova y otros pensadores). (FLORIANI, 2015, p. 4)

Trata-se, dentre outras coisas, da defesa de uma unidade latino-americana, mas valorizando as trajetórias que constituem os territórios, ou seja, por mais contraditório que pareça ser, é uma forma de valorizar a heterogeneidade dentro dessa homogeneidade. Em resumo, assumimos que América Latina possui elementos culturais, históricos, geográficos etc, que fazem ela se diferenciar de outras regiões do mundo ao passo que estas trajetórias que resultaram em uma "unidade" são diversas, por isso a tentativa em identificar territórios e estudá-los pelo que conhecemos como estudos de caso ou como foi dito acima, pelo viés da perspectiva do desenvolvimento territorial. Exemplos dessa questão são os inúmeros trabalhos sobre caiçaras e fandango (DIEGUES, 2017), faxinalenses, quilombolas, ruralidades e ambiente (FLORIANI, 2007; HALISKI, 2013; BRANDENBURG, 2018) entre outros.

[...] una matriz teórica que hace hincapié en los estudios poscoloniales y culturales y que no necesita partir de la oposición entre modernidad y tradición, 
prefiriendo considerar la situación histórica latinoamericana formada de modernidades en el plural, a la vez híbridas y heterogéneas. (FLORIANI, 2015,p.7)

Em uma dimensão mais ampla o que temos é uma diversidade de abordagens

Los autores que tienen sus referentes en las teorías de la pos colonialidad han formulado sus modelos interpretativos en fenómenos no fundamentalmente económicos o políticos (más bien de áreas de frontera en que se combinan aspectos objetivos y subjetivos, fenómenos culturales, psicosociales, étnicos, interculturales, de género, de sexualidad...), en la búsqueda de otros referentes teóricos diferentes de aquellos basados en autores con matrices nórdicas que pensaban desde sus matrices los destinos para las demás sociedades. (FLORIANI, 2015, p.7-8)

Esta perspectiva anuncia um processo de abertura da universidade para a diversidade. Por isso, uma grande leva de discussões em torno de uma ciência pública e útil (FLORIANI, 2015;2016) onde os sujeitos sociais são os responsáveis diretos pelo(s) caminho(s) que irão percorrer (na universidade isso pode se dar na construção do próprio currículo).

Uma situação bastante interessante que pode ser observada na cartografia social é o caso das benzedeiras de Rebouças/PR[3], que participaram de uma autocartografia e se localizaram/territorializaram em um mapa produzidos por elas. Por simples que possa parecer, tratamos isso como uma revolução e um ato de resistência, visto que estão afirmando que existem e lutam por seu espaço e práticas, como o direito de utilizar a floresta para extraírem medicamentos naturais. Esta forma de dizer "eu existo e estou aqui” resulta em reconhecimento e por consequência em ações, como adquirirem o reconhecimento oficial da Prefeitura e a confecção de carteiras, como aquelas de pessoas que fazem um curso técnico. A mudança substancial está exatamente na produção de um mapa que contrapõe o discurso oficial ou mapas e cartas "oficiais" produzidas por instituições como o exército. Nesses mapas, elas não existem e provavelmente não há interesse nessa existência. Ao se observar os casos de indígenas e outros povos iremos ter a mesma lógica, que é a da negação da existência destes grupos. Dizer “eu existo" pode significar conflitos por terras e territórios e resultar até mesmo em mortes.

Os atores individuais e coletivos que realizam atividades como estas citadas acima (defesa da ciência pública/útil, projetos...), estão em busca de uma horizontalidade de relações e que justifica a necessidade deste diálogo de saberes como possibilidade para a (re)construção de espaços para isso e que, passam necessariamente pela universidade.

[...] en la perspectiva de la ética en la investigación uno debe hacer las siguientes preguntas: ¿Cómo producir una ciencia prudente y pertinente? ¿Cómo 
establecer vínculos con el contexto (vinculación con el medio)? ¿Una investigación debe hacerse sólo con los objetos aunque estos son seres humanos? ¿La ciencia beneficia a toda la humanidad? En nombre del progreso ¿es válida toda investigación? ¿De qué ciencia estamos hablando: una ciencia corporativa de investigadores o una ciencia que se hace con todos los demás sujetos y actores involucrados? (FLORIANI, 2015,p.10)

\section{O DIÁLOGO EM FAVOR DE NOSSA "CASA COMUM"}

Na Encíclica Laudato Si' ("Louvado Sejas”), em consonância com as práticas do buen vivir, o Papa Francisco propõe um urgente desafio para unir toda a família humana, a fim de proteger a nossa "Casa Comum", na busca de um desenvolvimento sustentável e integral. A proposta de uma ecologia integral como novo paradigma ganha seu significado mais profundo e complexo a partir da figura geométrica do poliedro que espelha todas as parcialidades, mas que ao mesmo tempo mantém a sua originalidade.

A figura geométrica do poliedro remonta ao Timeu de Platão[4], mas que se transformou numa das características do Pontificado do Papa Francisco. A forma geométrica da esfera é lisa, sem facetas e representa a homogeneização. Já o poliedro caracteriza-se pelas suas múltiplas faces.

Por isso eu gosto da imagem do poliedro, uma figura geométrica com muitas caras distintas. O poliedro reflete a confluência de todas as particularidades que, nele, conservam a originalidade. Nada se dissolve, nada se destrói, nada se domina, tudo se integra. (Papa Francisco, 2019)

Assim, a Encíclica entende que a relação entre o homem e o meio ambiente não se resume ao paradigma econômico-tecnocrático, mas significa que existe uma íntima conexão entre o todo e as partes. Tudo "está interligado" "tudo está em relação" este não é só o mote como também a base do texto da Laudato Si' (Costa e Foglizzo, 2015, p.541). O cuidado da casa comum requer um diálogo com os diversos âmbitos de responsabilidade: político, científico, com os pobres, com as religiões e com a educação (COSTA e FOGLIZZO, 2015, p.485-496). Serão estes aspectos que abordaremos a seguir: O Diálogo com a Comunidade Internacional Sobre nossa casa Comum; Diálogo com as novas políticas nacionais e locais; Diálogo entre a política e a economia em função da realização humana e o Diálogo entre educação, espiritualidade ecológica e a ciência.

\section{O DIÁlOGO COM A COMUNIDADE INTERNACIONAL SOBRE NOSSA CASA COMUM}

Vivemos numa casa comum onde os problemas que afetam estilos de vidas afetam também toda humanidade. A interdependência exige pensarmos um projeto comum. Para tanto é necessário um consenso mundial sobre uma agricultura sustentável, formas de energia renováveis, 
gestão responsável dos recursos naturais (LS n.164). Embora o movimento ecológico tenha feito um percurso significativo através das cúpulas mundiais, não obstante, a falta de vontade política não permitiu avanços mais eficazes. $\mathrm{O}$ documento aponta para a necessidade de uma reação global e responsável por parte das instituições nacionais e internacionais que dialoguem para enfrentar o aquecimento global e o aumento da pobreza. Neste sentido, faz-se necessária uma nova relação entre economia e sistema financeiro. As questões ambientais não podem ser vistas puramente do ponto de vista mercadológico, do cálculo financeiro e da relação custo-benefício. Trata-se de abrir caminho para práticas diferentes de uso sustentável dos recursos naturais que levem em conta o valor real das coisas, das pessoas e, sobretudo dos mais pobres. Nas palavras do pontífice é necessário uma "corajosa revolução cultural” (LS n. 114), a mudança radical requer um novo ethos onde as relações humanas não sejam pautadas pela vontade de domínio e devastação. Uma nova forma de conceber o comportamento entre a humanidade e casa comum marcado pelo respeito e o cuidado. O Papa Francisco propõe uma ecologia integral onde os sistemas naturais e os sistemas sociais não estão separados e é preciso entendê-los e analisá-los em sua raiz comum. "Não há duas crises separadas: uma ambiental e outra social; mas uma única e complexa crise socio-ambiental" (LS n. 139). Para o Diretor da Revista Aggionamenti Sociali a ecologia integral não é um conteúdo que temos que adquirir, mas, sobretudo, uma ferramenta para ler a realidade a fim de intervir na sociedade visando a promoção da justiça (Costa, 2016, p.1). Daí que um sério enfrentamento dos problemas ecológicos desembocam também numa abordagem social. Escutar o "grito da terra" consequentemente leva-nos a escutar o "grito dos pobres".

Uma ecologia integral, neste sentido, pretende ser uma abordagem que leva em conta o sistema complexo que sustenta nossa "Casa Comum" "requer colocar em primeiro plano as relações de cada uma das partes individuais com as outras e com o todo" (COSTA, 2016, p.2). Uma compressão integrada da ecologia requer uma abordagem que seja capaz de articular os múltiplos cenários que estão conectados quais sejam: ecologia ambiental, ecologia econômica, ecologia social e ecologia quotidiana (Costa, 2016, p. 3).

A figura que melhor sintetiza a ecologia integral como um novo paradigma é o poliedro e não a esfera global onde não existe diferença entre o todo e as partes "cada ponto é equidistante do centro, não havendo diferença entre um ponto e o outro" (EG n.236). O modelo geométrico do poliedro, argumenta o Papa Francisco, "reflete a confluência de todas as partes que nele mantém a sua originalidade" (EG n.236). Dito isto, trata-se de superar um modelo homogeneizador que elimina a originalidade das partes e reconhecer que todos os seres vivos estão numa relação de 
interdependência. Este modelo requer o reconhecimento singular das partes em relação ao todo e que o todo sempre é maior que a parte. Deste modo, o modelo do poliedro é capaz integrar os sistemas naturais e os sistemas sociais.

\section{O DIÁlOGO COM AS NOVAS POLÍTICAS NACIONAIS E GLOBAIS}

As questões ambientais e relacionadas ao desenvolvimento econômico não podem ser analisadas apenas do ponto de vista das diferenças entre os países. Por isso, o diálogo deve girar entre "o que é o direito que estabelece as regras para as condutas permitidas à luz do bem comum" (LS n. 177).

A política revela sua dignidade e função quando trabalha com base em princípios que visem o bem comum e projetos de longo prazo. É oportuna uma política de base e local que respeite e valorize as experiências de solidariedade dos povos nativos, das cooperativas, das comunidades, organismos não governamentais e associações. Argumenta Francisco "se os cidadãos não controlam o poder político - nacional, regional e municipal -, também não é possível combater os danos ambientais" (LS n.179).

O diálogo e transparência nas tomadas de decisões são fundamentais para uma boa relação entre o meio ambiente e a humanidade, o que requer um diálogo transparente nos processos políticos e seus atores. A corrupção e a troca de favores tergiversam os debates e as tomadas de decisões sinceras sobre o meio ambiente. Qualquer programa desde o princípio deve ser "transparente e independente de qualquer pressão econômica ou política" (LS n. 183).

Se em nível mundial, as autoridades políticas se sentem impotentes em se comprometerem com o desenvolvimento de políticas públicas que valorizem energias renováveis em nível nacional e local as comunidades podem fazer toda a diferença. "Não se pode pensar em receitas uniformes, porque há problemas e limites específicos de cada país ou região" (LS n. 180).

Neste sentido, o Papa Francisco afirma - "É tanto o que se pode fazer" (LS n. 180). Ou seja, em nível local e nacional é possível promover popança energética, isto significa menor utilização de matéria prima e menos poluição. Uma economia mais solidária e sustentável com menos resíduos e mais reciclagem. Favorecer a agricultura diversificada em regiões mais pobres com técnicas sustentáveis e o incentivo a criação de associações, cooperativas e organizações de pequenos agricultores. 


\section{dí́logo ENTRE A POLÍTICA E A ECONOMIA EM FUNÇÃo DA REALIZAÇÃo HUMANA}

É imprescindível que, ao pensar em nossa "Casa Comum", a política dialogue com a economia. A economia não pode ser vista simplesmente como a riqueza das nações, mas também na perspectiva do cuidado da nossa casa comum. A via do lucro a qualquer custo "é uma distorção conceitual da economia: desde que aumente a produção pouco interessa que isso se consiga à custa de recursos futuros ou da perda da saúde do meio ambiente" (LS n.195).

Francis Bacon (1561-1626) dizia que a ciência por meio do seu método experimental devia “torturar" a natureza a fim de revelar sua verdade (Bacon, 2005). René Descartes (1596-1560), um dos principais racionalistas da modernidade em o Discurso sobre o Método dizia que o universo se assemelhava a uma máquina regida por leis e que os homens deveriam ser os senhores possuidores natureza (Descartes, 2005). Esta visão antropocêntrica nutriu a ciência moderna e gerou o paradigma tecnocrático.

Con l'espressione "paradigma tecnocratico" la LS intende l'assunzione di un attediagamento che vede in ogni realtà - fisica, biologica, umana o sociale che sia solo un oggetto infinitamente disponibile ala manipoloazione da parte dell'essere umano". (FOGLIZZO, 2016, p 597).

O paradigma tecnocrático resolveria todos os problemas humanos e ecológicos, portanto se apresenta como único modelo totalizante capaz de excluir qualquer alternativa (RIGGIO, 2016, p. 417). "Daqui passe-se facilmente a ideia de um crescimento infinito e ilimitado, que tanto entusiasmou os economistas, os teóricos da finança e da tecnologia" (LS n.106). Neste sentido, o Papa Francisco busca reinterpretar uma leitura antropocêntrica do Antigo Testamento de modo especial o livro do Gêneses, que diz: "Sejam fecundos, multipliquem-se, encham e submetam a terra: dominem os peixes do mar, as aves do céu e todos os seres vivos que rastejam sobre a Terra" $($ Gn 1,28). Esta visão reforçou uma antropologia cristã inadequada na qual o ser humano se sentia o senhor do mundo. A encíclica aponta para necessidade de uma nova relação com a realidade e possiblidade de uma conivência mais saudável em que o homem não é mais o "dominador do universo", mas um “administrador responsável” (LS n. 116).

De acordo com a encíclica Laudato Si' é importante que se estabeleça uma solidariedade compartilhada, capaz de superar o modelo competitivo e individualista. A via de ter muito de modo exclusivista já provou que é desumana e não universal. Daí a necessidade da política, da educação, e de uma autêntica espiritualidade para romper com essa lógica perversa. Um diálogo interdisciplinar para buscar alternativas que possam libertar do paradigma tecnocrático, sem deixar 
de reconhecer os avanços da ciência e os benefícios da tecnologia, que estão em função do desenvolvimento sustentável.

\section{O DIÁLOGO ENTRE EDUCAÇÃO, ESPIRITUALIDADE ECOLÓGICA E A CIÊNCIA}

O diálogo é benfazejo, pois ajuda a superar a fragmentação dos saberes, o isolamento, e a própria absolutização do saber. A Encíclica não quer definir as questões científicas, nem mesmo negar as valiosas contribuições da ciência. A fragmentação do saber tem seu valor no momento de aplicações concretas, mas não pode perder o sentido de totalidade. "Uma ciência, que pretenda oferecer soluções para grandes problemas, deveria necessariamente ter em conta tudo o que o conhecimento gerou nas outras áreas do saber, incluindo a filosofia e a ética social" (LS n.110).

Somente um diálogo franco e aberto permitirá superar a atual crise ecológica e religar o homem à natureza. Para tal, é necessária uma educação que alimente a consciência de pertença e a visão de compartilhamento da mesma casa comum. Esta articulação que conecta as partes com o todo requer o diálogo honesto transparente e inclusivo que leve em conta todas as perspectivas, isto é, um diálogo interdisciplinar.

Uma educação ambiental que permita ir além da informação científica, dos riscos ambientais e que leve em conta os "mitos" de um progresso ilimitado e do mercado neoliberal. Além disso, uma educação ética integral que ajude o sujeito a se encontrar consigo mesmo, com os outros, com as criaturas e com Deus. Criando uma nova rede de relações interligadas pelos laços de responsabilidade, solidariedade e compaixão.

Por fim, a ecologia integral "não pode prescindir de uma real e verdadeira opção existencial" (COSTA e FOGLIZZO, 2015, p.544). Neste sentido, o Papa apresenta São Francisco de Assis como "modelo de excelência (....) por uma ecologia integral (....) Vivida com alegria e autenticidade" (LS n. 10). São Francisco de Assis viveu com simplicidade e em total harmonia com Deus e as criaturas. Nele podemos perceber uma integral preocupação com as criaturas. Todas eram tratadas como irmãs até mesmo aquelas consideradas inúteis (ervas daninhas). "Nele se nota até que ponto são inseparáveis a preocupação pela natureza, a justiça para com os pobres, o empenho na sociedade e a paz interior” (LS n. 10). São Francisco manifestou uma relação de maravilhamento e gratuidade com a natureza e com os pobres. "A pobreza e a austeridade de São Francisco de Assis não eram simplesmente um ascetismo exterior, mas algo de mais radical: uma renúncia a fazer da realidade um mero objeto de uso e domínio" (LS n.11). Tal comportamento não significa "romantismo irracional", mas uma abertura a categorias que transcendam um 
comportamento das ciências exatas e um viés utilitarista dos resultados e cálculos econômicos centrados somente na eficiência e nos lucros.

Um diálogo que entrelaça todas as perspectivas e os diversos níveis da sociedade que extrapola os muros da Igreja Católica que busca sensibilizar, os místicos, cientistas, ativistas, pessoas com posições contrárias, militantes, movimentos populares etc. Os desafios parecem ser enormes. O Papa Francisco por meio do convite ao diálogo abre novas possibilidades, novas situações históricas e alternativas para repensarmos o futuro de nossa casa comum.

A preocupação com nossa "Casa Comum" nos faz prosseguir no caminho do diálogo por isso nem tudo "está perdido" (LS n.205). O ser humano sempre é capaz de superar-se e de regenerar-se. Nenhum sistema ou condicionalismo é capaz de aprisionar totalmente a liberdade e a criatividade humana. Os seres humanos são capazes de abrir novos caminhos, novas alternativas.

\section{CONSIDERAÇÕES FINAIS}

A noção de crise civilizatória está ancorada nos modos de vida que tornam tudo mercadoria, inclusive os recursos naturais. Sendo assim, faz-se necessário um rompimento com esta lógica que compromete a vida na Terra. Tem-se assistido o quanto isso é necessário, visto que espaços como a Amazônia e a Floresta Atlântica estão em processo ininterrupto de destruição. A solução está dentro desses biomas, pois eles co-evoluiram com povos e comunidades que ajudaram a tornar esses biomas o que eles são hoje. Exemplo dessa solução são povos originários, ribeirinhos, pescadores artesanais, quilombolas, faxinalenses, camponeses em geral, que possuem modos de vida pautados no buen vivir. Isto significa a negação da capitalização e destruição de tudo em nome de um progresso que ninguém saber dizer o que é de fato, além de ser destruição e enriquecimento de uns poucos. Assim, seus modos de vida são essencialmente a chave para outro(s) mundos possíveis.

Como apontado no texto, a própria universidade está sendo (re)significada a ponto de evidenciar aquilo que é, ou deveria ser, o seu propósito, ou seja, valorizar e mostrar a universalização do conhecimento, e não somente aquele pautado na rigidez da academia e seus métodos de se fazer e dizer o que é ciência. Portanto, se os saberes de povos e comunidades são tão importantes quanto aquele produzido na academia, nos resta ir até as comunidades e fazer com que elas venham até nós. Para isso acontecer muitos muros devem ser quebrados e o diálogo de saberes socioambientais é uma das muitas maneiras para tal. 
Podemos dizer que a Encíclica Papal representa um significativo avanço, sobretudo, por valorizar o diálogo como método para resolver problemas controversos e mobilizar ativistas, religiosos, sociedade civil, cientistas entre outros na defesa de nossa "Casa Comum". Um dos limites da Encíclica está no fato de não reconhecer os direitos da natureza, ou seja, a ética ecológica exige alargar direitos para além dos humanos e reconhecer que a natureza tem valores em si para além do simplesmente útil para o ser humano[5]. Embora a Encíclica teça uma crítica à tecnocracia e ao antropocentrismo, ela mantém uma interpretação segundo a qual o homem aparece como um ser com dignidade especial.

\section{REFERÊNCIAS}

ACOSTA, A. o Buen vivir: uma oportunidade de imaginar outro mundo. In: Um campeão visto de perto: uma análise do modelo de desenvolvimento brasileiro. (org) Heinich Böll Stiftung, 2012.

BACON, F. Novum Organum ou verdadeiras indicações acerca da interpretação da natureza. Trad Aluysio Reis de Andrade. São Paulo: Nova Cultural, 2005. (Col. Os Pensadores).

BÍBLIA. Português. Tradução de Padre Antônio Pereira Figueredo. Rio de Janeiro: Encyclopaedia Britannica, 1980. Edição Ecumênica.

CAPRA, F. A teia da vida: uma nova compreensão científica dos sistemas vivos. São Paulo: Editora Cultrix, 2006.

COSTA, G. FOGLIZZO, PAOLO. Laudato Si': un'enciclica poliedro, in la Rivista del clero Italina, 7-8 (2015), 485-496.

DESCARTES, R. Discurso do Método. Trad. Enrico Corvisieri. São Paulo: Nova Cultura, 2005. (Col Os Pensadores).

FLORIANI, D. Conhecimento, meio ambiente \& globalização. $1^{\mathrm{a}}$ ed. (2004), $4^{\mathrm{a}}$ reimp. Curitiba: Juruá, 2008.

FLORIANI, D. Desafios epistemológicos para o pensamento socioambiental contemporâneo: a produção do conhecimento institucional e sua relação com os demais saberes e práticas. Revista Guaju, 2016.

Las ciências sociales en America Latina: lo permanente y transitorio, preguntas y desafíos de ayer y hoy. Revisat Latinoamericana - Polis, 2015.

FLORIANI, N. Avaliação das terras pelos agricultores ecológicos de Rio Branco do Sul-PR: uma abordagem geo-sócio-agronômica da paisagem rural. (Tese- Doutorado em Meio Ambiente e Desenvolvimento-UFPR), 2007.

FOGLIZZO, Paolo. Un'economia per la cura dela casa comune. Rivista Aggiornamenti Sociali. Agosto-settembre 2016, pp. 996-603. 
FRANCISCO, Papa. Carta Encíclica Laudato Si': sobre o cuidado da casa comum. São Paulo :Paulinas, 2015.

FRANCISCO, Papa. Exortação Apostólica Evangelii Gaudium., 24. Disponível em $<$ http://w2.vatican.va/content/francesco/pt/apost_exhortations/documents/papafrancesco_esortazione-ap_20131124_evangelii-gaudium.html>, acessado em 20/06/2019.

FRANCISCO, Papa.Discurso. $<$ http://consciencia.net/discurso-papa-francisco-aos-participantesencontro-mundial-de-movimentos-populares/>, acessado dia 26/06/2019.

GUDYNAS, E. La senda biocéntrica: valores intrínsecos, derechos de la naturaleza y justicia ecológica. Tabula Rasa, Bogotá, n. 13, p. 45-71, julio-diciembre, 2010.

GUISO, A. Potenciando la Diversidad: Diálogo de saberes, una práctica hermenéutica colectiva. Medellín, Febrero, 2000.

HALISKI, A. M. Arranjo produtivo local das Gêmeas do Iguaçu: uma alternativa para o desenvolvimento territorial? Dissertação de Mestrado (Programa de Pós-graduação em Ciências Aplicadas, UEPG), 2007.

Formação e atualidade histórica de um grupo de agricultores entre Santa Catarina e Paraná: disputas sobre os usos da natureza e ambiente. Programa de pós-graduação em Sociologia (Tese), UFPR,2013.

HALISKI, A. M.; MACHADO, M. L.; HALISKI, V. C. F.; MARTINS, P. Um convite à extensão nas ilhas: entre a realidade e os desafios de prática pedagógica para licenciados de ciências sociais. Revista Conexão UEPG, 2016.

JUNGES, José Roque. Ética ecológica: antropocentrismo ou biocentrismo?. Perspectiva Teológica, Belo Horizonte, v. 33, n. 89, p.33-66, 2001.

LEFF, E. Complexidade, racionalidade ambiental e diálogo de saberes. In: Educação \& Realidade. p.17-24, set./dez. 2009.

. Epistemologia Ambiental. São Paulo: Cortez Editora, 2001.

Racionalidad ambiental y diálogo de saberes: sentidos y senderos de un futuro sustentable. In: Desenvolvimento e Meio Ambiente, n. 7, p. 13-40, jan./jun. Editora UFPR, 2003 Vozes, 2001.

Saber ambiental: sustentabilidade, racionalidade, complexidade, poder. Petrópolis, RJ:

LUNA, E. P.; MOYA, N. A. Dialogo de saberes y proyectos de investigación en la escuela. In: Educere: artículos arbitrados. Año 12, nº42, p. 455-460, jul./ago./set. 2008.

PORTO-GONÇALVES, C. W. Amazônia, encruzilhada civilizatória: tensões sociais em curso. 1 Ed, Rio de Janeiro, Consequência Editora, 2017.

LEWITZKI, T. Nova Cartografia Social dos Povos e Comunidades Tradicionais do Brasil conhecimentos tradicionais e mobilizações políticas: o direito de afirmação da identidade de 
benzedeiras e benzedores, municípios de Rebouças e São João do Triunfo, Paraná. Boletim Informativo. Projeto Nova Cartografia Social dos Povos e Comunidades Tradicionais do Brasil, Alfredo Wagner Berno de Almeida... [et al]. Manaus: Editora da Universidade do Estado do Amazonas, 2012.

SANTOS, Boaventura de Sousa. A crítica da razão indolente: contra o desperdício da experiência. São Paulo: Cortez 2005.

Para uma Sociologia das ausências e uma sociologia das emergências. In: Conhecimento Prudente para uma vida decente: Um discurso sobre as ciências revisitado (org) Boaventura de Sousa Santos. São Paulo: Cortez, 2004.

SCHAVELZON, S. Plurinacionalidad e vivir bien/buen vivir: dos conceptos leídos desde Bolívia y Ecuador post-constituyentes. Ediciones Abya-Yala, 2015.

SILVA, S. R. Ética pública e formação humana. Educação e Sociedade -Campinas, vol. 27, n. 96 Especial, p. 645-665, out. 2006.

VIVEIROS DE CASTRO, E. Imagens da natureza e da sociedade. In: A inconstância da alma selvagem: e outros ensaios de antropologia. São Paulo: Cosac \& Naify, 2002.

[1] A discussão da Rede evoluiu e hoje está em vias de consolidação a criação de uma universidade itinerante (UNITINERANTE), cujo propósito é desenvolver pesquisa e extensão para além dos muros das instituições escolares. http://redecaslacepial.blogspot.com/2019/08/casla-promoveu-no-dia-29-julho-primeira.html

[2] Ações vinculadas ao grupo de $\quad$ pesquisa $\quad$ Interconexões http://gpinterconexoes.blogspot.com.br/2016/10/interconexoes-tem-projeto-aprovado-no.html

[3] Esta e outras informações estão disponíveis na página http://novacartografiasocial.com/ e no boletim informativo de abril de 2012 file:///C:/Users/antonio/Downloads/Informativo-1_Conhecimentos-Tradicionais-identidadeBenzedeiras-Parana.pdf

[4] A Figura geométrica remonta a PLATÃO. Timeu- Crítias. Tradução Rodolfo Lopes. Coimbra. Editor Centro de Estudos Clássicos e Humanísticos, 2010. Especialmente os n. 193,194, 195, 196 e 297.

[5] Não temos o espaço suficiente para abordar o impasse entre a ética antropológica e a ética biopocêntrica ou ética ecológica. Para aprofundar o tema indicamos alguns autores: CAPRA, Fritjof. A teia da vida: uma nova compreensão científica dos sistemas vivos. São Paulo: Editora Cultrix, 2006. GUDYNAS, E. La senda biocéntrica: valores intrínsecos, derechos de la naturaleza y justicia ecológica. Tabula Rasa, Bogotá, n. 13, p. 45-71, julio-diciembre, 2010. JUNGES, José Roque. Ética ecológica: antropocentrismo ou biocentrismo?. Perspectiva Teológica, Belo Horizonte, v. 33, n. 89, p.33-66, 2001. 